\title{
De slimme stad: grote beloften, weerbarstige praktijk
}

\author{
Bart Karstens, Linda Kool en Rinie van Est ${ }^{*}$
}

Het concept van de slimme stad is al circa twintig jaar in zwang (Mitchell 1995; Schaffers e.a. 2012), maar de afgelopen jaren is de aantrekkingskracht ervan sterk toegenomen. Dat komt mede door technologische ontwikkelingen op het gebied van Internet of Things, kunstmatige intelligentie en 5G. De slimme stad is op dit moment misschien wel het populairste stedelijke ideaal. ${ }^{1}$

Veel gemeenten in Nederland voelen zich aangetrokken tot informatie- en communicatietechnologie omdat het werken met data efficiënte oplossingen belooft voor de uitdagingen waar zij voor staan. De lokale overheid is derhalve een belangrijke speler op het gebied van digitale innovatie. ${ }^{2}$ Een 'smart city'-strategie geeft een gemeente een visie en een mandaat voor haar beleid, en brengt mensen en middelen in beweging om innovatieve projecten van de grond te krijgen.

De grote beloften worden vaak ondersteund door beelden waarin de slimme stad wordt voorgesteld als een schone, serene en hemelsblauwe oase waar alles efficiënt en foutloos verloopt. De praktijk is echter veel weerbarstiger. Ten eerste staat de term 'smart city' niet voor een stad als geheel, maar eerder voor een relatief losse verzameling van digitaliseringsprojecten. Sommige onderzoekers hebben dan ook voorgesteld om het adjectief 'smart' maar helemaal weg te laten, omdat het gebruik ervan een reëler beeld van digitalisering in de stad in de weg zou staan (Greenfield 2013). Ten tweede blijken slimmestadprojecten complexe ondernemingen te zijn. Gemeenten lopen tegen

* Dr. B. Karstens is onderzoeker op het gebied van kunstmatige intelligentie en de digitale samenleving bij het Rathenau Instituut. L. Kool MSc MA is coördinator binnen het thema Digitale Samenleving verbonden aan het Rathenau Instituut. Prof. dr. ir. Q.C. van Est is als coördinator binnen het thema Slimme Samenleving werkzaam bij het Rathenau Instituut. $\mathrm{Hij}$ is tevens hoogleraar Technology Assessment and Governance aan de Technische Universiteit Eindhoven.

1 Voor een overzicht van stedelijke idealen in de geschiedenis zie Eaton (2001).

2 Mazzucato (2015) laat zien dat een investerende overheid onontbeerlijk is voor innovatie, omdat vaak pas na overheidsinvesteringen de private sector volgt. Voorbeelden die zij geeft zijn het internet, geneesmiddelen en biotechnologie. 
een heel scala van juridische, economische, bestuurlijke, maatschappelijke en ethische uitdagingen aan. Niet zelden zorgen deze uitdagingen voor vertraging of zelfs staking van de projecten.

Er is geen blauwdruk voorhanden waarmee slimmestadprojecten tot een succes kunnen worden gemaakt. Wat goed werkt en wat niet moet dus in de praktijk worden uitgevonden (Van Est e.a. 2018). Het Rathenau Instituut heeft onderzocht hoe dit in de praktijk in de gemeente Eindhoven is gegaan. We hebben ons afgevraagd tegen welke problemen Eindhoven is aangelopen, welke maatregelen de gemeente heeft genomen om die het hoofd te bieden, en in hoeverre die maatregelen hebben gewerkt (Karstens e.a. (n.n.g.)).

We hebben ons op Eindhoven gericht omdat deze gemeente in Nederland een pioniersrol heeft vervuld en als een van de eerste steden digitaliseringsprojecten is gaan uitvoeren. Daar komt bij dat Eindhoven dit van meet af aan op een maatschappelijk verantwoorde manier heeft willen doen, door te werken met vier principes voor de digitale samenleving die Eindhoven zelf heeft opgesteld, in samenwerking met de gemeente Amsterdam (Eindhoven \& Amsterdam 2017). Doel van ons onderzoek is niet geweest om het beleid van de gemeente Eindhoven te evalueren. Het ging ons vooral om lessen te trekken uit het verloop van de projecten, bijvoorbeeld met betrekking tot de werking van de vier principes.

Deze principes moeten zorgen dat digitale innovatie niet ten koste gaat van publieke waarden als privacy, autonomie en sociale rechtvaardigheid (zie ook Kool e.a. 2017). Ze zetten onder meer in op transparantie door te eisen dat de verzamelde gegevens ('open data') en de code van de gebruikte algoritmen ('open source') openbaar toegankelijk worden gemaakt. Eind 2019 heeft de Vereniging van Nederlandse Gemeenten (VNG) vrijwel identieke principes omarmd en tot uitgangspunt voor alle Nederlandse gemeenten gemaakt (VNG 2019). Elders zijn nog meer principes voor de digitale samenleving opgesteld, die elkaar grotendeels overlappen. ${ }^{3}$ De principes zijn een vorm van 'soft law': ze hebben wel een regulerende werking, maar die kan niet wettelijk worden afgedwongen.

Volgens de Britse wetenschapper Rob Kitchin is er in het onderzoek naar de slimme stad een tekort aan empirische casestudies, afgezien van typische voorbeelden die telkens opnieuw door iedereen worden

3 Bijvoorbeeld Ministerie van BZK 2019; GroenLinks 2019; Meijer e.a. 2019. Internationaal wijzen we op Eurocities 2019 en Morozov \& Bria 2018. 
gebruikt (Kitchin 2015). De door ons gevolgde empirische onderzoeksstrategie komt tegemoet aan deze kritiek. In Karstens e.a. (n.n.g.) hebben de auteurs van dit artikel gekeken naar de inzet van sensoren in het uitgaansgebied aan het Stratumseind, de aanleg van een slim lichtnetwerk, het gebruik van data in de jeugdzorg en het gebruik van een digitaal platform als hulpmiddel bij het verduurzamen van woningen. De selectie van de cases is gebaseerd op het type digitale technologie in de projecten (sensoren, Internet of Things) en het maatschappelijke domein waarin het project plaatsvond (veiligheid, leefbaarheid, duurzaamheid, sociaal welzijn). Op deze manier wilden we een breed overzicht krijgen van mogelijke kwesties waar partijen mee te maken kunnen krijgen. De casusbeschrijvingen zijn gebaseerd op interviews met alle betrokken partijen, een interne workshop met de gemeente Eindhoven en achtergrondmateriaal over de casus, aangedragen door betrokkenen of afkomstig uit openbare bronnen.

In dit artikel lichten wij één typisch voorbeeld uit het rapport: de plaatsing van slimme lantaarnpalen. We beschrijven eerst de doelstellingen en het verloop van het project. Daarna gaan we in op de uitdagingen waar dit project mee te maken heeft gekregen. Achtereenvolgens zijn dat het realiseren van economische kansen, de aansluiting van juridische kaders op de nieuwe praktijk die door digitalisering ontstaat, en het organiseren van de samenwerking tussen overheid, bedrijven en burgers. In de conclusie vatten we onze bevindingen samen en komen we tot een aantal aanbevelingen.

\section{Het project ‘Jouw Licht Op 040’}

In een aantal wijken in Eindhoven is in de periode 2017-2019 een netwerk van slimme lantaarnpalen geplaatst. ${ }^{4}$ Slimme lantaarnpalen kunnen met veel meer functies worden uitgerust dan alleen de straat verlichten. Denk bijvoorbeeld aan sensoren die luchtkwaliteit, geluidsniveau, hoeveelheid verkeer en aantal mensen kunnen meten. Slimme lantaarnpalen kunnen daarom worden ingezet voor surveillancedoeleinden of voor het effectiever regelen van de verkeersdoorstroming. Een verzameling lantaarnpalen kan ook een elektriciteitsnetwerk vormen voor het opladen van mobiele telefoons of - bij verzwaring van 
het netwerk - elektrische auto's. Op het gebied van milieubeheer en duurzaamheidsbeleid geven de lantaarnpalen ondersteuning bij het vergroten van elektrisch rijden door veel meer oplaadpunten aan te bieden. Energiebesparing is ook te realiseren door de intensiteit van de verlichting automatisch aan te passen aan de behoefte op straat. Belangrijk is ook dat de ledbuizen die in de slimme lantaarnpalen zitten zuiniger zijn dan de tl-buizen van de standaardlantaarnpalen. Tijdens het ontwikkelen van 'Jouw Licht Op 040' had de gemeente Eindhoven vooral het vergroten van duurzaamheid voor ogen, naast het verbeteren van de leefbaarheid en veiligheid in de wijken (Eindhoven 2014). Maar ook andere toepassingen werden overwogen, zoals koppeling met hulpdiensten en het verbeteren van verkeersmobiliteit. Men wilde het verder aan bedrijven en burgers zelf overlaten om slimme toepassingen te bedenken. De verwachting was dat economische bedrijvigheid vanzelf zou gaan ontstaan wanneer bedrijven de kans zouden krijgen innovatieve diensten aan te bieden op basis van de data die via het slimme lichtnetwerk verzameld gaan worden. De gemeente heeft bewoners van de wijken waar de lantaarnpalen geplaatst werden actief betrokken bij het bedenken van toepassingen. Uit diverse consultatierondes en 'bootcamps' kwamen vooral toepassingen naar voren om de veiligheid en de leefbaarheid in de buurten te vergroten. Vanaf 2017 was de gemeente met de partners Philips (armaturen), Heijmans (lantaarnpalen) en Atos (software) reeds begonnen met het plaatsen van de nieuwe lichtmasten. In de vijf proefgebieden van het project zijn in totaal 2.700 slimme lantaarnpalen neergezet. Eind 2019 heeft de gemeente Eindhoven echter de stekker uit het project getrokken. Er is wel een lichtnetwerk aangelegd, maar vrijwel zonder dat er slimme toepassingen zijn uitgevoerd, ook niet die welke na de consultatierondes met de bewoners van de wijken waren geselecteerd. Alleen op Strijp S zijn lantaarnpalen met geluidsdetectie geïnstalleerd en in Woensel Noord zijn slimme lantaarnpalen met sensoren geplaatst, die zorgen dat de lamp aanspringt of harder gaat branden als er mensen langskomen.

Het is opmerkelijk dat de beslissing om te stoppen met het project midden in de voorgenomen proefperiode van vijf jaar is genomen. Uit een evaluatie met alle betrokken partijen blijkt dat daar twee redenen voor zijn geweest, namelijk gebrekkige samenwerking tussen de deelnemende partijen die uiteenlopende belangen en verwachtingen 
hadden én tegenvallende resultaten. ${ }^{5}$ Wij zijn in ons onderzoek een aantal knelpunten tegengekomen die deze evaluatie onderschrijven.

\section{Realiseren van economische kansen}

De deelnemende partijen in het 'Jouw Licht Op 040'-project waren de gemeente Eindhoven, een aantal bedrijven én burgers, die gevraagd zijn slimme toepassingen voor hun straat of wijk te bedenken. De geringe reikwijdte van de burgerinitiatieven bleek echter problematisch te zijn. Een groot bedrijf als Philips gaf aan dat het voor hen niet opportuun is om apart toepassingen te ontwikkelen voor lokale, specifieke doeleinden. Voor bedrijven moeten de bedachte toepassingen renderen. Grote bedrijven willen snel opschalen. Voor hen is één proefwijk, of zelfs één stad, te klein. Voor de gemeente Eindhoven riep te snel meegaan in schaalvergroting echter het spookbeeld op van 'vendor lock-in': de overheid wordt afhankelijk van het technologiebedrijf, verzwakt daarmee haar onderhandelingspositie en verliest mogelijk controle over dataverwerking. Kleine bedrijven zijn wellicht geschikter om lokale initiatieven te realiseren, maar zij hebben vaak niet de financiële ruimte om op lange termijn te investeren. Het ophalen en selecteren van toepassingen via burgerinspraak kost bijvoorbeeld veel tijd. De casus leert ons dat de deelnemende partijen nog onvoldoende zijn ingesteld op de extra tijdsinvestering en de ontwikkeling van nieuwe verdienmodellen die voor dit soort digitaliseringsprojecten nodig blijken te zijn. ${ }^{6}$

De gemeente Eindhoven heeft zich bij de uitvoering van het project vastgehouden aan de vier principes voor verantwoord datagebruik. Eén principe stelt dat data die zijn verzameld in de openbare ruimte, mits ontdaan van tot individuele personen herleidbare gegevens, ook openbaar beschikbaar moeten blijven voor iedereen, ten behoeve van transparantie en privacybescherming. Aangezien bedrijven een gelijke toegang tot de datasets wordt geboden, hebben ze ook een gelijke kans om slimme toepassingen op die data te ontwikkelen. Dit zou moeten helpen om 'vendor lock-in' te voorkomen. Het probleem hiermee is dat bedrijven die kosten maken om data te vergaren hun competitieve voordeel kwijt zijn als ze die data vervolgens gratis met iedereen moe- 
ten delen. Dat kan ertoe leiden dat bedrijven zich terugtrekken. Het 'open data'-principe kan zodoende economische bedrijvigheid blokkeren en zelfs de continuïteit van een slimmestadproject in gevaar brengen.

\section{Grensvervaging en het afstemmen van juridische kaders ${ }^{7}$}

Bij slimmestadtoepassingen draait alles om data. Die data worden door iedereen gegenereerd die zich in de publieke ruimte manifesteert, en kunnen worden gebruikt voor zowel publieke als private doeleinden. In slimmestadprojecten ontstaat een netwerk van objecten (sensoren), data en belanghebbende partijen (overheid, instellingen, bedrijven én burgers). Voorheen gescheiden rollen en verantwoordelijkheden raken in het netwerk met elkaar vervlochten. ${ }^{8}$ Dat leidt tot onzekerheid en brengt belangrijke juridische kwesties naar voren over welke kaders, voor welke partijen, van toepassing zijn. We geven twee voorbeelden van deze grensvervaging uit de casus slimme lantaarnpalen.

Ten eerste is het niet duidelijk wie als dataverzamelaar moet worden aangemerkt in het project. Is dat de gemeente of het private consortium Philips/Heijmans? De gemeente Eindhoven heeft de palen en de armaturen, inclusief de grond waar die op staan, in eigendom gehouden. Maar het beheer van de openbare verlichting en het databeheer zijn (onder voorwaarden) overgedragen aan de bedrijven. De regels voor het hergebruik van data zijn vastgelegd in de Wet hergebruik van overheidsinformatie. Het Philips/Heijmans-consortium voert wel een publieke taak uit, maar het is geen openbaar lichaam. De regels voor hergebruik gelden daarom niet. Het consortium is dan ook niet wettelijk verplicht om de data die het verzamelt te delen. Dat staat op gespannen voet met wat de gemeente beoogt via het 'open data'-prin-

7 In deze paragraaf maken we gebruik van de juridische analyse van Joost Gerritsen, die is uitgevoerd voor Karstens e.a. (n.n.g.).

8 Deze Quadruple Helix (voor het eerst voorgesteld in Carayannis \& Campbell 2009) is een uitbreiding van het al meer dan twintig jaar bestaande idee van een Triple Helix, waarin overheid, kennisinstellingen en ondernemers samenwerken. In het Triple Helix-model hebben de drie partijen duidelijk afgebakende doelen. Onderzoek levert kennis op, ondernemers proberen daarmee economische groei en voorspoed te realiseren en de overheid oefent als wetgevende macht controle uit en zorgt voor een adequate kennisinfrastructuur en gunstig innovatieklimaat (Etzkowitz \& Leydesdorff 1995). In een Quadruple Helix zijn deze doelen minder duidelijk af te bakenen. 
cipe. Als derde partijen toegang willen hebben tot de data, om bijvoorbeeld een nieuwe applicatie op te ontwikkelen, dan moeten zij daarbij kunnen. Om te voorkomen dat ongeoorloofde concurrentie ontstaat, zijn nadere afspraken tussen de gemeente en het consortium nodig ófwel moet de wetgeving op landelijk niveau worden aangepast. Ten tweede is ook de juridische status van het slimme lichtnetwerk nog ongewis. Een openbaar verlichtingsnetwerk wordt traditioneel gereguleerd als een elektriciteitsnetwerk. Het slimme lichtnetwerk is een elektriciteitsnetwerk, maar tegelijk ook een ICT-netwerk. ICT-netwerken, of preciezer, openbare elektronische communicatienetwerken, vallen van oudsher onder de Telecommunicatiewet. Die wet bevat techniekonafhankelijke regels voor aanbieders van elektronische communicatienetwerken en -diensten. Zo moeten telecomaanbieders bijvoorbeeld in verband met privacybescherming locatiegegevens verwijderen of anonimiseren als die niet meer nodig zijn voor het realiseren van de communicatie. Elektriciteitsnetwerken vielen vanaf 1998 onder de Elektriciteitswet, die eisen stelt aan het transport en de levering van elektriciteit, maar niet met betrekking tot privacybescherming. In de nieuwe Wet voortgang energietransitie, die vanaf mei 2018 van kracht is (Staatsblad 2018, 129), is er meer over privacybescherming opgenomen, maar blijft een spanningsveld bestaan. Enerzijds staat er dat netbeheerders informatie openbaar moeten maken die voor de markt van belang is. Anderzijds bepaalt de wet dat de netbeheerder moet voorkomen dat vertrouwelijke gegevens in handen komen van derden.

Bovengenoemde twee voorbeelden van grensvervaging kenmerken de nieuwe praktijk die door datagestuurd werken ontstaat. Zowel de Telecommunicatiewet als de Wet voortgang energietransitie bepaalt dat ondernemingen hun verantwoordelijkheid moeten nemen met betrekking tot privacybescherming. Philips heeft zich ook mede aan het 'Jouw Licht Op 040'-project verbonden om te leren hoe het bedrijf op een verantwoorde manier om moet gaan met vragen rondom privacy en hergebruik van data. De Algemene verordening gegevensbescherming (AVG) stelt dat voorafgaand aan dataverzameling duidelijk moet zijn voor welk doel dat gebeurt (doelbinding), zodat de privacyrisico's kunnen worden ingeschat. Het idee is dat doelbinding automatisch wijst op een vigerend juridisch kader. Onze voorbeelden laten zien dat dat niet zo evident is. Daar komt bij dat data die kunnen worden hergebruikt weleens andere doelen kunnen gaan dienen dan 
vooraf te bepalen is. Geaggregeerde datasets kunnen door combinaties met andere datasets in sommige gevallen opnieuw persoonsgevoelig worden. Het is lastig om dit risico vooraf in te schatten. Er liggen kortom nog diverse juridische uitdagingen voor ons. Op zowel Europees als nationaal niveau zal de juridische status van het slimme lichtnetwerk moeten worden verhelderd. Waar het gaat om het sluiten van samenwerkingsovereenkomsten met private partners moet de gemeente zelf actie ondernemen, ofschoon de VNG werkt aan standaardisering van contracten die datazeggenschap regelen. Het is misschien niet nodig om geheel nieuwe wetgeving te ontwikkelen. De bestaande wetgeving, zoals de AVG, de Telecommunicatiewet, de Elektriciteitswet, de Wet voortgang energietransitie en de Crisis- en herstelwet, hoewel ontwikkeld om de leveringszekerheid, kwaliteit, toegankelijkheid en betaalbaarheid van traditionele infrastructurele netwerken te waarborgen, lijkt ook goed toepasbaar te zijn op de implementatie van het slimme lichtnetwerk. Bestaande juridische kaders moeten wel worden toegesneden op de nieuwe praktijk die draait om dataverzameling en dataverwerking. ${ }^{9}$

\section{Maatschappelijk draagvlak}

Naast bovengenoemde economische en juridische uitdagingen moet de gemeente ook zorgen voor voldoende draagvlak voor het digitaliseringsproject. Hoe ziet een wijk er straks uit als lantaarnpalen gaan dienen als laadpalen? Wat voor data verzamelt de paal en wat vinden bewoners daar eigenlijk van? Het helpt natuurlijk niet om bewoners actief te betrekken bij het ontwikkelen van slimme toepassingen en vervolgens na een lang traject niets met die toepassingen te doen. Er ligt een bestuurlijke uitdaging om de uiteenlopende belangen en verwachtingen van alle deelnemende partijen verstandig te managen. ${ }^{10}$ En wat betekent intensief gebruik van de palen eigenlijk voor het energiegebruik? De gemeente verwacht dat de 2.700 lampen die nu geplaatst zijn een verwachte energiebesparing gaan opleveren van $400.000 \mathrm{KWh}$ per jaar. Is dat de $€ 2,9$ miljoen waard die de gemeente in

9 Zie in dit verband Pront-van Bommel e.a. 2011; Lavrijssen e.a. 2016; De Hollander e.a. 2017.

10 In de evaluatie van het project wordt geopperd om professionele expertise aan te trekken om de samenwerking in de Quadruple Helix beter te coördineren. Zie jouwlichtop040.nl. 
het project heeft gestoken (Eindhovens Dagblad, 4 september 2019)? ${ }^{11}$ En zou die energiebesparing uiteindelijk gaan opwegen tegen de energiebelasting die benutting van de mogelijkheden van de slimme lantaarnpalen met zich mee gaat brengen? Als het hoofddoel van het 'Jouw Licht Op 040'-project, meer duurzaamheid, uit beeld raakt, kan ook dat zorgen voor onvoldoende draagvlak in de samenleving voor de slimme lantaarnpalen.

\section{Conclusie}

Door veranderende combinaties van maatschappelijke uitdagingen en technische mogelijkheden wordt de overheid van tijd tot tijd uitgedaagd om haar bestuur en beleid opnieuw vorm te geven. Illustratief is in dit verband het pamflet The city of tomorrow and its planning uit 1929 van de architect Le Corbusier. Le Corbusier signaleerde eind jaren twintig een 'urbane crisis', die was ontstaan door de bevolkingsgroei, de toename van mobiliteit (auto's, treinen) en het achterblijven van voorzieningen voor de laagste klassen. Het moderne leven vroeg volgens hem om radicaal andere manieren van bouwen, plannen van voorzieningen en regelen van het verkeer.

In onze tijd creëren vooral de nieuwe technische mogelijkheden, het werken met digitale middelen, een nieuwe praktijk waar de (lokale) overheid haar weg nog in moet vinden. Niet alleen in Eindhoven, maar overal ter wereld blijken slimmestadprojecten lastig van de grond te krijgen, ook in iconische projecten als Songdo in Zuid-Korea of het 'Sidewalk Labs'-project van Google in Toronto. ${ }^{12}$ Technische kennis is niet het belangrijkste struikelblok. Het gaat vooral om het vinden van ethische en juridische spelregels omtrent dataverwerking, het afstemmen van verantwoordelijkheden in een samenwerkingsstructuur met meerdere partijen, inclusief een belangrijke rol daarin voor burgers, en het ontwikkelen van nieuwe verdienmodellen op basis van dataverzameling.

Het is dus niet verwonderlijk dat sommige gemeenten ervoor kiezen om een 'slimme volger' te zijn. Leeuwarden (2019) kijkt bijvoorbeeld

11 Daar moet wel bij worden aangetekend dat de lantaarnpalen aan vervanging toe waren. De vervangingskosten zouden dus sowieso zijn gemaakt.

12 Onlangs heeft Google zich abrupt teruggetrokken uit dit project vanwege 'economische onzekerheid'. 
liever eerst de kat uit de boom en wil pas instappen als duidelijk is geworden tegen welke problemen pionierende gemeenten aanlopen. Eindhoven heeft een andere keuze gemaakt en is als pionier met een aantal projecten van start gegaan. De vier principes die de gemeente had opgesteld, fungeerden daarbij als randvoorwaarden en hielpen om te navigeren in de nieuwe praktijk. Zo waren ze bijvoorbeeld richtinggevend voor de afspraken over dataverwerking die de gemeente met private partners heeft gemaakt. Ook is er ruime aandacht geweest in Eindhoven voor de bescherming van privacy en zijn er diverse vormen van 'privacy by design' toegepast, zoals het anonimiseren van gegevens, zodat deze niet meer tot individuele personen herleidbaar zijn.

Op deze maatregelen kan in de toekomst worden voortgebouwd. Onze analyse laat echter zien dat er nog belangrijke uitdagingen overblijven. Wettelijke kaders moeten nog beter worden afgestemd op de digitale realiteit. Er ontstaan bijvoorbeeld publiek-private entiteiten die zowel publieke als commerciële taken uitvoeren en de activiteiten van deze entiteiten zijn nog onvoldoende geborgd door de wet. Het is misschien niet nodig om nieuwe wetgeving te ontwikkelen, wellicht is aanpassing van bestaande wetgeving afdoende.

We hebben ook gezien dat het 'open data'-principe zonder nadere bepalingen kan botsen met het realiseren van economische kansen. Het is aan te bevelen om dit principe aan te vullen met specifieke voorwaarden omtrent het (her)gebruik van data. Mogelijkheden die verkend kunnen worden, zijn het opleggen van beperkingen aan de openbaarheid van de datasets en het onderwerpen van ieder hergebruik aan een deugdelijkheidstoets, waarmee onder meer het gerechtvaardigd belang van het hergebruik moet worden bekeken (Berlee 2017).

Zowel aanpassing van de wet als het 'updaten' van principes voor de digitale samenleving vraagt om actie op landelijk niveau. De uitdaging om de samenwerking in de Quadruple Helix beter te coördineren kan echter lokaal worden opgepakt. Intussen krijgen we steeds meer inzicht in slimmestadprojecten. Nieuwe initiatieven, waaronder projecten met slimme lantaarnpalen in andere gemeenten, kunnen hun voordeel doen met recent ontwikkelde proceskennis. ${ }^{13}$ Ook kan er 
worden gekeken naar ervaringen in andere landen. ${ }^{14}$ Ten slotte hebben gemeenten in Nederland baat bij het zo veel mogelijk uitwisselen van kennis en ervaringen die ze met de uitvoering van slimmestadprojecten opdoen. De in dit artikel besproken casus laat zien hoeveel dat kan opleveren. De kwesties die naar boven zijn gekomen, sluiten in algemene zin aan bij eerdere studies van het Rathenau Instituut, die laten zien dat innovaties alleen overleven wanneer ze maatschappelijk ingebed raken in technologische infrastructuur, markten en productieketens, wet- en regelgeving én waarden, opvattingen en routines van gebruikers en het bredere publiek (Rathenau Instituut 2019). Deze vier aspecten komen heel duidelijk naar voren in slimmestadprojecten. Omdat die zich over het algemeen nog in een pionierende fase bevinden, valt met betrekking tot elk van de vier aspecten juist in de praktijk nog veel te leren.

\section{Literatuur}

\section{Berlee 2017}

A. Berlee, 'Volledige openbaarheid: het doel voorbij', Weekblad voor Privaatrecht, Notariaat en Registratie 2017, afl. 7169, p. 844-852.

\section{Van den Broek e.a. 2020}

J. van den Broek, I. van Elzakker, T. Maas \& J. Deuten, Voorbij lokaal enthousiasme. Lessen voor de opschaling van living labs, Den Haag: Rathenau Instituut 2020.

\section{Carayannis \& Campbell 2009}

E.G. Carayannis \& D.F.J. Campbell, "Mode 3" and "Quadruple Helix": Toward a 21st century fractal innovation ecosystem', International Journal of Technology Management (46) 2009, afl. 3/4, p. 201-234.

\section{Chourabi e.a. 2012}

H. Chourabi e.a., 'Understanding smart cities: An integrative framework', in: HICSS '12: Proceedings of the 2012 45th Hawaii International Conference on Systems Science, 2012, p. 2289-2297.

14 Zo is in Vlaanderen Antwerpen als test- en experimenteerstad aangewezen. Wat daar goed gaat, kan vervolgens in andere steden worden toegepast (Van Est 2020, p. 21). 


\section{Eaton 2001}

R. Eaton, Ideal cities: Utopianism and the (un)built environment, Antwerpen: Mercatorfonds 2001.

\section{Eindhoven 2014}

Gemeente Eindhoven, Selectieleidraad Implementatie Visie en Roadmap stedelijke verlichting, Eindhoven 2030, 2014.

\section{Eindhoven \& Amsterdam 2017}

Gemeente Eindhoven \& gemeente Amsterdam, 'Spelregels voor de digitale infrastructuur in de stad' (brief van wethouders Depla en Ollongren), 20 februari 2017.

\section{Van Est 2020}

R. van Est, 'Zoektocht naar het goede digitale leven. Zet mensen en waarden centraal bij het vormgeven van digitale innovatie', in: J. Rabaey, R. van Est, P.-P. Verbeek \& J. Vandewalle, Maatschappelijke waarden bij digitale innovatie. Wat, wie en hoe? (KVAB Denkersprogramma 2019), Brussel: Koninklijke Vlaamse Academie van België voor Wetenschappen en Kunsten 2020, p. 11-24.

\section{Van Est e.a. 2018}

R. van Est, E. de Bakker, J. van den Broek, J. Deuten, P. Diederen, I. van Keulen, I. Korthagen \& H. Voncken, Waardevol digitaliseren. Hoe lokale bestuurders vanuit publiek perspectief mee kunnen doen aan het 'technologiespel', Den Haag: Rathenau Instituut 2018.

\section{Etzkowitz \& Leydesdorff 1995}

H. Etzkowitz \& L. Leydesdorff, 'The Triple Helix - universityindustry-government relations. A laboratory for knowledge-based economic development', EASST Review (14) 1995, p. 14-19.

\section{Eurocities 2019}

Eurocities, Principles on citizen data. 10 data principles for the common good, 2019, http:// nws.eurocities.eu/MediaShell/ media/EUROCITIES_citizen_ data_principles_final.pdf.

\section{Greenfield 2013}

A. Greenfield, Against the smart city, New York: Do Projects 2013.

\section{GroenLinks 2019}

Wetenschappelijke Bureau GroenLinks, Handvest voor de slimme stad. Technologie sturen op basis van waarden, Utrecht: WBGL 2019. 


\section{Helberger e.a. 2018}

N. Helberger, J. Pierson \&

T. Poell, 'Governing online platforms. From contested to cooperative responsibility', The Information Society (34) 2018, afl. 1, p. 1-14.

\section{De Hollander e.a. 2017}

G. de Hollander, M. Vonk,

D. Snellen \& H. Huitzing, Mobiliteit en elektriciteit in het digitale tijdperk. Publieke waarden onder spanning, Den Haag: Uitgeverij PBL 2017.

\section{Karstens e.a. (n.n.g.)}

B. Karstens, L. Kool \& R. van Est, m.m.v. I. Korthagen, E. de Bakker, J. Gerritsen, M. Biesiot \& R. Riemens, Voeten in de aarde. Datagestuurde innovatie in de stad, Den Haag: Rathenau Instituut (n.n.g.).

\section{Kitchin 2015}

R. Kitchin, 'Making sense of smart cities. Addressing present shortcomings', Cambridge Journal of Regions, Economy and Society (8) 2015, p. 131-136.

\section{Kool e.a. 2017}

L. Kool, J. Timmer, L. Royakkers \& R. van Est, Opwaarderen. Borgen van publieke waarden in de digitale samenleving, Den Haag: Rathenau Instituut 2017.

\section{Lavrijssen e.a. 2016}

S. Lavrijssen, A. Marhold \&

A. Trias Lopez, The changing world of the DSO in a smart energy system environment. Key issues and policy recommendations, Brussel: CERRE 2016.

\section{Le Corbusier 1929}

Le Corbusier, The city of tomorrow and its planning, New York: Dover Publications 2013.

\section{Leeuwarden 2019}

Gemeente Leeuwarden, Leeuwarder digitale agenda, 2019.

\section{Mazzucato 2015}

M. Mazzucato, De ondernemende staat. Waarom de markt niet zonder de overheid kan, Amsterdam: Nieuw Amsterdam 2015.

\section{Meijer \& Thaens 2018}

A. Meijer \& M. Thaens, 'Urban technological innovation. Developing and testing a sociotechnical framework for studying smart city projects', Urban Affairs Review (54) 2018, afl. 2, p. 363-387.

\section{Meijer e.a. 2019}

A. Meijer, M. Schäfer \& M. Branderhorst, 'Principes voor goed lokaal bestuur in de digitale samenleving. Een aanzet tot een normatief kader', Bestuurswetenschappen (73) 2019, afl. 4, p. 8-23. 


\section{Ministerie van BZK 2019}

Ministerie van BZK, Behoorlijk datagebruik in de openbare ruimte. Aanbevelingen voor nieuw beleid, Den Haag: Ministerie van Binnenlandse Zaken en Koninkrijksrelaties 2019.

\section{Mitchell 1995}

W.J. Mitchell, City of bits. Space, place, and the infobahn, Cambridge, MA: MIT Press 1995.

\section{Morozov \& Bria 2018}

E. Morozov \& F. Bria, Rethinking the smart city. Democratizing urban technology, New York: Rosa Luxemburg Stiftung 2018.

\section{Pront-van Bommel e.a. 2011}

S. Pront-van Bommel, S. Akerboom, G. Buist, A. Huygen \&

A. Ottow (red.), Smart grid pilots. Handvatten voor toepassing van wet- en regelgeving (in opdracht van Agentschap NL), Amsterdam/Utrecht/Delft: Universiteit van Amsterdam/Universiteit Utrecht/TNO 2011.

\section{Rathenau Instituut 2019}

Rathenau Instituut, Missiegericht innovatiebeleid in uitvoering (bericht aan het parlement), 2019.

\section{Schaffers e.a. 2012}

H. Schaffers e.a., Smart cities as innovation ecosystems sustained by the future internet (EU white paper, technical report, hal-00769635), 2012.

\section{VNG 2019}

Vereniging van Nederlandse Gemeenten, Principes voor de digitale samenleving. Deel 1. De digitale openbare ruimte, Den Haag: VNG Realisatie 2019. 